\title{
Incorporation of cerium atoms into Al-free Beta zeolite framework for catalytic application
}

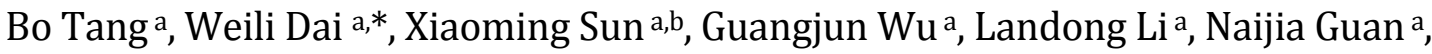 \\ Michael Hunger ${ }^{b}$ \\ ${ }^{a}$ Collaborative Innovation Center of Chemical Science and Engineering (Tianjin) \& Key Laboratory of Advanced Energy Materials Chemistry of Ministry of \\ Education, College of Chemistry, Nankai University, Tianjin 300071, China \\ ${ }^{\mathrm{b}}$ Institute of Chemical Technology, University of Stuttgart, 70550 Stuttgart, Germany
}

\section{A R T I C L E I N F O}

Article history:

Received 4 November 2014

Accepted 4 December 2014

Published 20 June 2015

Keywords:

Ce-Beta zeolite

Post-synthesis

Dealumination

Ring-opening hydration

Epoxide

\section{A B S T R A C T}

Ce(IV)-containing zeolite Beta was successfully prepared by a reproducible and scalable two-step post-synthesis strategy. This consists of creating vacant $\mathrm{T}$ sites that are associated with silanol groups by the dealumination of the H-Beta zeolite and a subsequent dry impregnation of the resultant Si-Beta zeolite with cerium (IV) isopropoxide. XRD, FT-IR, UV-Vis and ${ }^{1} \mathrm{H}$ MAS NMR confirmed that Ce(IV) was successfully incorporated into the Beta zeolite framework by the post-synthesis procedures and that they exist as isolated atoms with tetrahedral coordination. The mechanism of Ce incorporation into the framework of Beta zeolite was confirmed by DRIFT spectroscopy. The ring-opening hydration of epoxides to their corresponding 1,2-diols was selected as a model reaction for an evaluation of the catalytic performance of the as-synthesized Ce-Beta zeolite.

(C) 2015, Dalian Institute of Chemical Physics, Chinese Academy of Sciences.

Published by Elsevier B.V. All rights reserved.
Zeolites are widely used as catalysts in the refining, petrochemical, and fine chemical industries because of their high specific surface area, large pore volume, uniform microporous channels and excellent thermal and hydrothermal stability $[1,2]$. The incorporation of transition metals into the zeolite framework can deliver heteroatomic zeolite materials with new remarkable catalytic activity. Transition metals such as $\mathrm{Ti}$, $\mathrm{Sn}, \mathrm{Zr}, \mathrm{V}$, and $\mathrm{Nb}$, have been introduced into the framework of different zeolitic structure allowing their application in new fine chemical processes as highly active and selective heterogeneous catalysts [3]. One of the most interesting classes of materials is highly hydrophobic BEA-type metallosilicate zeolites. They exhibit superior catalytic activity in novel biomass-related transformations in water. Nevertheless, few studies have been reported on isomorphous substitution with lanthanides (Ln) in BEA zeolites and the resultant catalytic properties of these microporous crystalline materials [4,5]. A feasible method for the preparation of framework-substituted lanthanide zeolites still remains a significant challenge because of size incompatibility between lanthanides and the $\mathrm{Si}^{4+}$ ion. The reason for this is the longer $\equiv \mathrm{Si}-\mathrm{O}-\mathrm{Ln} \equiv$ bonds with large bond-angle strain in the Ln-substituted rigid silica networks.

For the preparation of heteroatomic zeolites, different methods such as conventional hydrothermal crystallization [6], dry-gel conversion [7], fluoride modification [8] and microwave-assisted methods [9] have been adopted. Although highly active metallosilicates can be obtained using direct synthesis strategies, most of these routes are complicated and time-con-

\footnotetext{
* Corresponding author. Tel/Fax: +86-22-23500341; E-mail: weilidai@nankai.edu.cn

This work was supported by the National Natural Science Foundation of China (21373119), the Ministry of Education of China (IRT13022, IRT13R30); 111 Project (B12015), and Deutsche Forschungsgemeinschaft.
} DOI: 10.1016/S1872-2067(14)60277-1 | http://www.sciencedirect.com/science/journal/18722067 | Chin. J. Catal., Vol. 36, No. 6, June 2015 
suming resulting in both a lack of reproducibility and feasibility for large-scale synthesis. Therefore, alternative post-synthesis strategies have been developed for the preparation of these materials [10-14]. Recently, we reported an improved post-synthesis approach for the preparation of Ti(IV)- and Sn(IV)-containing Beta zeolites $[15,16]$. The dry impregnation (DI) of a dealuminated Beta zeolite with an organometallic precursor followed by simple thermal treatment has been shown to be an attractive route for the incorporation of metal ions into a zeolite framework. A significant amount of active centers can be created.

In this study, we adopted the following strategy to incorporate $\mathrm{Ce}(\mathrm{IV})$ into the framework of Beta zeolite. Vacant $\mathrm{T}$ sites with associated silanol groups were first created by treating commercial H-Beta zeolite with a concentrated nitric acid solution and the resulting Si-Beta zeolite was subsequently ground with the organic Ce precursor, Ce(IV) isopropoxide, to give a Si-Beta/Ce(iso- $\left.\mathrm{OC}_{3} \mathrm{H}_{7}\right)_{4}$ mixture, which was further calcined to give Ce-Beta zeolite $[15,16]$. The as-synthesized sample was characterized by X-ray diffraction (XRD), FT-IR, DRIFT, diffuse reflectance ultraviolet-visible (UV-Vis) spectroscopy and multinuclear solid-state nuclear magnetic resonance (NMR) spectroscopy. The catalytic performance was evaluated by the hydration of epoxides.

To determine if structural changes occurred during the post-synthesis procedures, the XRD patterns of the parent H-Beta together with those of the post-treated samples were collected and are shown in Fig. 1. All the samples are characteristic of typical BEA topology with comparable diffraction intensity apart from the zeolite framework collapse during the dealumination and Ce incorporation processes. The dealumination and incorporation of Ce species into the framework of the Beta zeolite were evident by the contraction/expansion of the framework as shown by the detectable changes in the position of the diffraction peak (302) at $2 \theta=22^{\circ}$. This is similar to that previously reported by Dzwigaj's group $[17,18]$. The $\mathrm{d}_{302}$ spacing, obtained from the corresponding $2 \theta$ value decreased from $0.3921 \mathrm{~nm}\left(\mathrm{H}-\right.$ Beta, $\left.2 \theta=22.64^{\circ}\right)$ to $0.3871 \mathrm{~nm}$ (Si-Beta, $2 \theta=$ $22.95^{\circ}$ ). This suggests the contraction of the Beta matrix after the dealumination procedure. The $\mathrm{d}_{302}$ spacing of the Ce-Beta zeolite after dry impregnation increased to $0.3946 \mathrm{~nm}(2 \theta=$

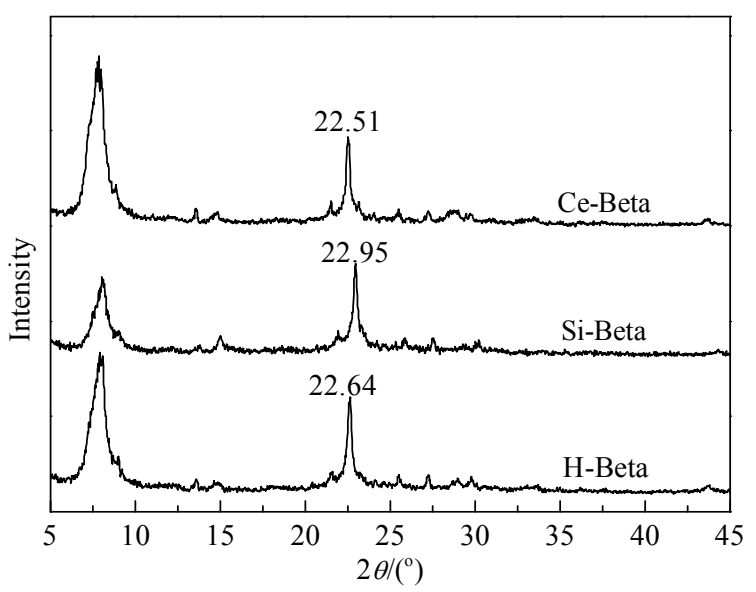

Fig. 1. XRD patterns of the H-Beta, Si-Beta, and Ce-Beta samples.
Table 1

Physicochemical properties of the H-Beta, Si-Beta, and Ce-Beta samples.

\begin{tabular}{lcccc}
\hline Catalyst & $\mathrm{Si} / \mathrm{Al}^{\mathrm{a}}$ & $\begin{array}{c}\text { Ce loading a } \\
(\mathrm{wt} \%)\end{array}$ & $\begin{array}{c}\text { Surface area } \\
\left(\mathrm{m}^{2} / \mathrm{g}\right)\end{array}$ & $\begin{array}{c}\text { Micropore volume }^{\mathrm{c}} \\
\left(\mathrm{cm}^{3} / \mathrm{g}\right)\end{array}$ \\
\hline H-Beta & 13.5 & - & 590 & 0.204 \\
Si-Beta & $>1800$ & - & 620 & 0.220 \\
Ce-Beta & $>1800$ & 3.4 & 600 & 0.195 \\
\hline
\end{tabular}

a Determined by ICP. ${ }^{b}$ Obtained by the BET method. ${ }^{c}$ Calculated from the $t$-plot.

$22.51^{\circ}$ ). This phenomenon is clear evidence of BEA framework expansion indicating the successful incorporation of Ce into the Beta zeolite.

The physicochemical properties of H-Beta, Si-Beta, and Ce-Beta are summarized in Table 1. All the samples have a similar BET surface area (590-620 $\mathrm{m}^{2} / \mathrm{g}$ ) and micropore volume $\left(0.195-0.220 \mathrm{~cm}^{3} / \mathrm{g}\right)$. This confirms that the textural properties of the Beta zeolite were well preserved after dealumination and Ce incorporation. ICP analysis results reveal that the $n_{\mathrm{Si}} / n_{\mathrm{Al}}$ ratio of the parent H-Beta increases significantly from 13.5 to more than 1800 for the dealuminated Si-Beta and this indicates that the latter is essentially free of Al. After the incorporation of Ce the actual Ce loading determined by ICP is close to the design value indicating the efficiency of the dry impregnation method.

The FT-IR spectra of H-Beta, Si-Beta and Ce-Beta samples are given in Fig. 2. No obvious IR bands are present in 900-1000 $\mathrm{cm}^{-1}$ for the parent H-Beta sample while a band at $\sim 948 \mathrm{~cm}^{-1}$ is present for the Si-Beta sample. This newly-formed band can be assigned to the presence of a large amount of defect sites as a result of the extraction of $\mathrm{Al}$ atoms from the Beta framework [19]. After the incorporation of Ce the $948 \mathrm{~cm}^{-1}$ band was absent indicating an interaction between Ce(IV) isopropoxide and the defect sites. Furthermore, a new band centered at $967 \mathrm{~cm}^{-1}$ is present in the Ce-Beta sample and this is indicative of the successful incorporation of Ce into the framework of the Beta zeolite.

To investigate the coordination behavior of the incorporated Ce species, a diffuse reflectance UV-Vis spectrum was obtained for the as-synthesized Ce-Beta sample. As shown in

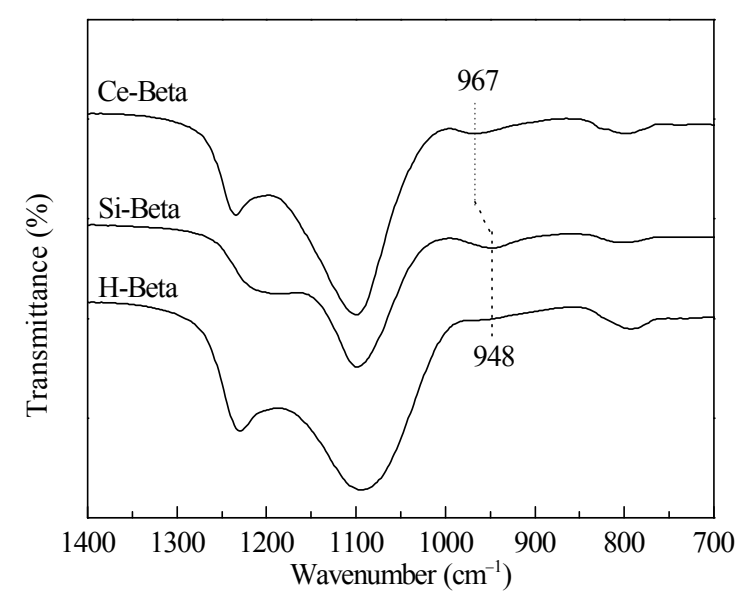

Fig. 2. FT-IR spectra showing the skeletal vibration region for H-Beta, Si-Beta, and Ce-Beta. 


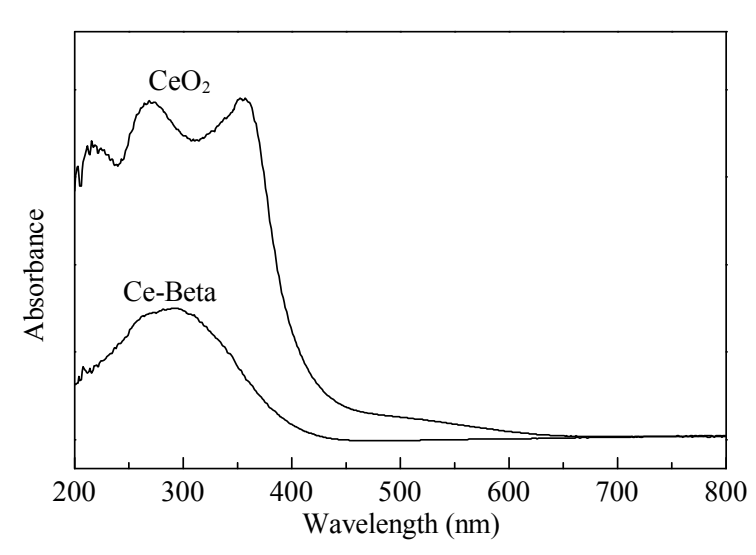

Fig. 3. UV-Vis spectra of the Ce-Beta and $\mathrm{CeO}_{2}$ samples.

Fig. 3, the Ce-Beta zeolite sample has a main strong absorbance maximum at $\sim 290 \mathrm{~nm}$ in strong contrast to the $\mathrm{CeO}_{2}$ reference sample. According to the literature [5,20], this band may be attributed to a ligand-to-metal charge transfer from $\mathrm{O}^{2-}$ to $\mathrm{Ce}^{4+}$. Therefore, incorporated Ce is present in a highly isolated tetrahedrally coordinated form and it is generally accepted to be the catalytically active Ce species during liquid-phase oxidation reactions.

The dealumination of H-Beta and the incorporation of Ce are associated with the evolution of the silanols related to the vacant sites that formed during the post-synthesis procedures. This is further supported by the DRIFT spectra (Fig. 4). Several characteristic bands are present for the dehydrated H-Beta zeolite sample in the hydroxyl stretching region of 3800-3400 $\mathrm{cm}^{-1}$. The bands at 3740 and $3605 \mathrm{~cm}^{-1}$ come from isolated external Si-OH groups and the bridging hydroxyls in $\mathrm{Si}-\mathrm{OH}-\mathrm{Al}$, respectively. Additional bands are present at 3660 and 3525 $\mathrm{cm}^{-1}$, and these are associated with the Al-OH of the extra-framework aluminum species and the hydrogen-bonded Si-OH groups, respectively $[15,16]$. As shown in Fig. 2, the treatment of $\mathrm{H}$-Beta with a concentrated $\mathrm{HNO}_{3}$ solution results in the absence of the bands at 3660 and $3605 \mathrm{~cm}^{-1}$, which are representative of $\mathrm{Al}$ species. This suggests the complete elimi-

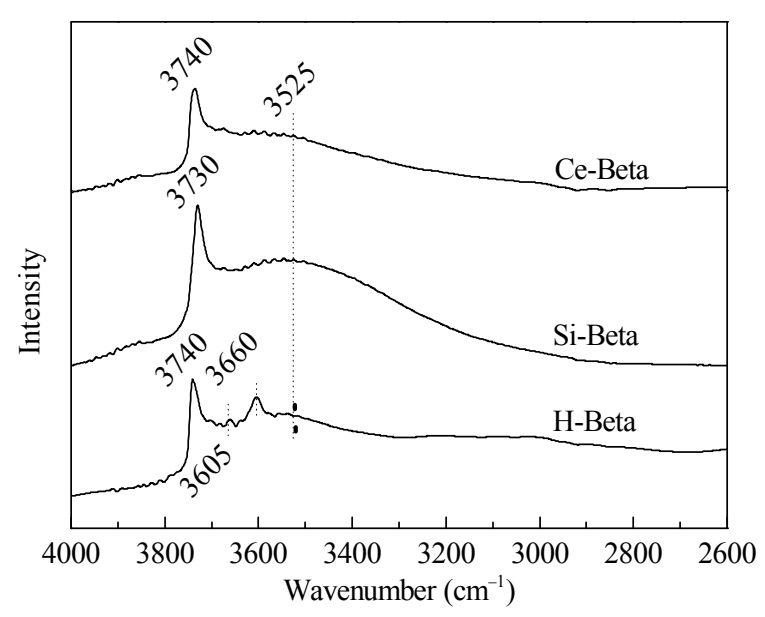

Fig. 4. DRIFT spectra in the hydroxyl stretching vibration region of H-Beta, Si-Beta, and Ce-Beta. nation of $\mathrm{Al}$ atoms from the Beta framework. Simultaneously, an increase in the intensity of the band at $3730 \mathrm{~cm}^{-1}$ because of the isolated internal $\mathrm{Si}-\mathrm{OH}$ groups and at $3525 \mathrm{~cm}^{-1}$ because of the H-bonded silanols occurs indicating the formation of vacant $\mathrm{T}$ sites during acid treatment. This is in accordance with earlier studies [10-12,17,18]. Subsequent dry impregnation of the Si-Beta zeolite sample with Ce(IV) isopropoxide results in an obvious decrease in the intensity of the bands at 3730 and $3525 \mathrm{~cm}^{-1}$ because of the hydroxyls located at the vacant $\mathrm{T}$ sites. This observation indicates a reaction between the Ce species and the silanols proving their incorporation into the Beta zeolite framework.

In the ${ }^{1} \mathrm{H}$ MAS NMR spectra of H-Beta, a strong signal is present at $1.5 \mathrm{ppm}$ and two weak signals are present at 2.5 and 3.9 ppm (Fig. 5). These signals come from silanol groups in the framework defects (1.5 ppm), hydroxyl groups from the extra-framework Al species (2.5 ppm), and bridging hydroxyl (Si(OH)Al) groups (3.9 ppm), respectively [21]. The dealumination process is characterized by the absence of hydroxyl groups associated with the framework as well as the extra-framework Al species, which are responsible for the signals at 2.5 and 3.9 ppm, respectively [21]. The intensity of the signal from the $\mathrm{Si}-\mathrm{OH}$ groups in the framework defects (1.5 ppm) increases significantly and a new signal is present at $2.7 \mathrm{ppm}$. This is assigned to the $\mathrm{Si}-\mathrm{OH}$ groups that are involved in hydrogen bonding to neighboring framework oxygen species within the silanol nests [15]. The incorporation of Ce into Si-Beta zeolite results in the absence of silanol groups in the framework defects and the hydroxyl nests. The remaining unreacted silanols have a chemical shift of $1.7 \mathrm{ppm}$.

Based on IR and ${ }^{1} \mathrm{H}$ MAS NMR spectroscopy results, the Ce-Beta zeolite can be prepared in a manner similar to the synthesis of Ti- and Sn-Beta zeolite as reported in our previous work $[15,16]$. The strategy employed in this study consists of creating vacant $\mathrm{T}$ sites with associated silanols by the dealumination of $\mathrm{H}$-Beta zeolite with $\mathrm{HNO}_{3}$ and the subsequent dry impregnation of the resulting Si-Beta zeolite with organic ce-

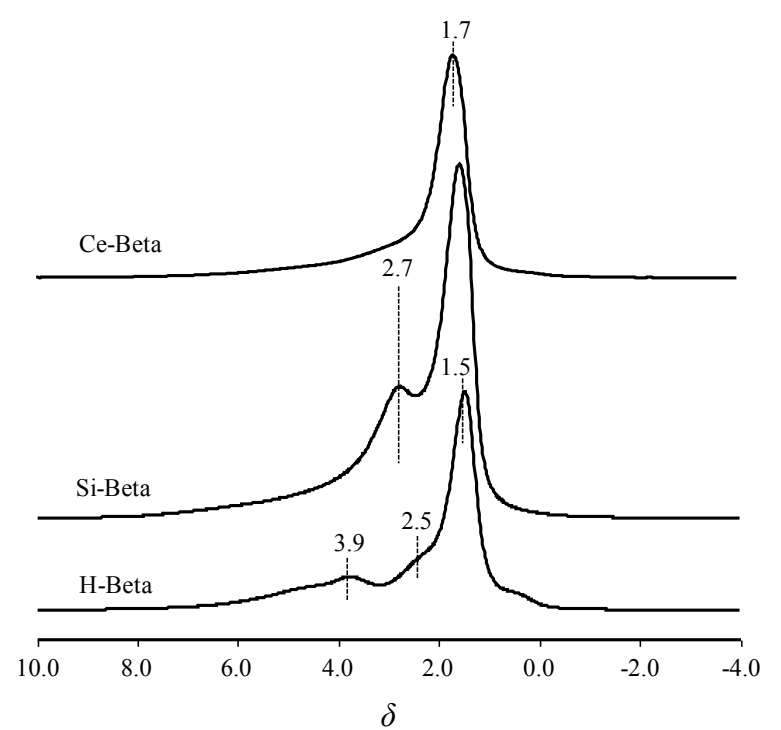

Fig. 5. ${ }^{1} \mathrm{H}$ MAS NMR spectra of the dehydrated H-Beta, Si-Beta, and Ce-Beta samples. 


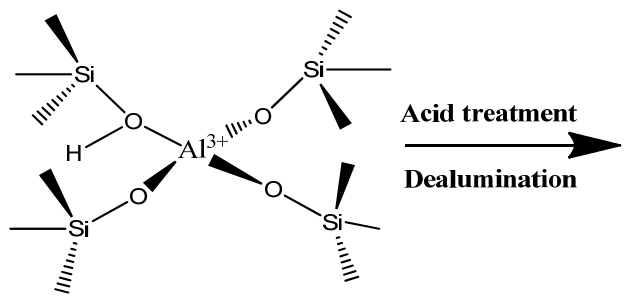

Tetrahedral Al(III)

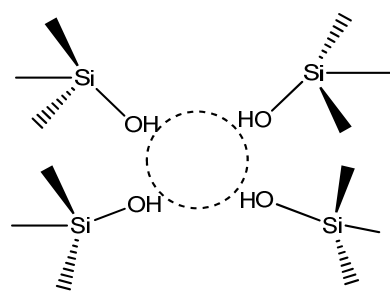

Vacant T-atom site

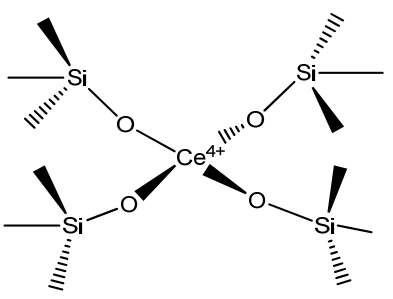

Tetrahedral Ce(IV)

Scheme 1. Schematic representation of the incorporation of tetrahedrally coordinated Ce(IV) species into Beta zeolite.

rium(IV) isopropoxide, as illustrated in Scheme 1.

The ring-opening hydration of epoxides was selected as a model reaction to evaluate the catalytic performance of the post-synthesized Ce-Beta zeolite. Target 1,2-diols are widely used as important intermediates for the production of polyester resins, antifreeze, cosmetics, and other products. Typically, epoxide hydration is performed in a $25 \mathrm{~mL}$ round-bottom glass vessel with a cryogenic-liquid condenser under atmospheric pressure. In our test the vessel was charged with a mixture of $10 \mathrm{mmol}$ epoxide, $20 \mathrm{mmol} \mathrm{H}_{2} \mathrm{O}$ and $0.1 \mathrm{~g}$ catalyst, which was mixed vigorously by a magnetic stirrer. Samples from the reaction were qualitatively analyzed using a Shimadzu 2010 GC (Japan, Agilent HP-5MS column, $30 \mathrm{~m} \times 0.25 \mathrm{~mm} \times 0.25 \mu \mathrm{m}$; FID detector) with octanol as the internal standard. The GC peaks were identified by comparison with the retention time of known standard samples and also by a Shimadzu GC-MS QP2010 SE equipped with an Agilent HP-5MS column. As shown in Table 2, considerable epoxide conversion as well as high selectivity toward 1,2-diols was obtained (ethers from the dimerization/trimerization were the main by-products) accompanied by the stoichiometric incorporation of water in the ring-opening reaction. However, under identical reaction conditions very little product $(1 \%)$ was obtained for the cyclohexene oxide hydration reaction in the absence of the catalyst. The use of Si-Beta zeolite as the catalyst also resulted in low catalytic activity $(<3 \%)$. The influence of preparation method, i.e. DI (dry impregnation), WI (wet impregnation) or SSIE (solid-state ion-exchange) on the activity of Ce-Beta zeolite during the ring-opening hydration of epoxides was also investigated.

Table 2

Hydration of different epoxide substrates catalyzed by Ce-Beta zeolite.

\begin{tabular}{|c|c|c|c|c|}
\hline Substrate & $\begin{array}{c}\text { Temperature } \\
(\mathrm{K})\end{array}$ & $\begin{array}{l}\text { Time } \\
(\mathrm{h})\end{array}$ & $\begin{array}{c}\text { Epoxide } \\
\text { conversion (\%) }\end{array}$ & $\begin{array}{l}\text { 1,2-Diol selec- } \\
\text { tivity (\%) }\end{array}$ \\
\hline & 333 & 12 & 89.5 & $>99$ \\
\hline & 353 & 12 & 45.8 & 90.5 \\
\hline & 333 & 6 & 51.2 & 72.9 \\
\hline
\end{tabular}

Reaction conditions: $10 \mathrm{mmol}$ epoxide, $20 \mathrm{mmol} \mathrm{H}_{2} \mathrm{O}, 0.1 \mathrm{~g}$ catalyst. * Reaction was performed in a $10 \mathrm{~mL}$ autoclave under a $\mathrm{N}_{2}$ pressure of $1.0 \mathrm{MPa}$.
Outstanding catalytic performance for Ce-Beta zeolite was only obtained when using the DI route. This shows the superiority of the two-step post-synthesis strategy that was developed for the preparation of Ce-Beta in this study. The hydration of epoxides is generally carried out with a large excess of water $\left(n_{\mathrm{H} 2 \mathrm{O}} / n_{\text {epoxide }}=20-25\right)$ at elevated temperatures $(>413 \mathrm{~K})$ and/or in the presence of solvents to obtain high substrate conversion as well as the desired product selectivity. The catalytic results obtained with a lower $n_{\mathrm{H} 2 \mathrm{O}} / n_{\text {epoxide }}$ of 2 confirm that the Ce(IV)-containing Beta zeolite can be regarded as a promising catalyst for the sustainable production of 1,2-diols.

In conclusion, a simple and scalable two-step post-synthesis procedure was developed to prepare Ce-Beta zeolite. This includes the dealumination of H-Beta zeolite and dry impregnation of the resultant Si-Beta zeolite with the organic precursor, Ce(IV) isopropoxide. We thus present a novel and simple preparation method for the synthesis of lanthanide-containing zeolites and we also expand its catalytic application.

\section{References}

[1] Corma A. Chem Rev, 1997, 97: 2373

[2] Cundy C S, Cox P A. Chem Rev, 2003, 103: 663

[3] Moliner M. Dalton Trans, 2014, 43: 4197

[4] Guo H C, Wang X S, Zou B S. Chin J Catal (郭洪臣, 王祥生, 邹本三. 催化学报), 1997, 18: 185

[5] Wu Y J, Wang J, Liu P, Zhang W, Gu J, Wang X J. J Am Chem Soc, 2010, 132: 17989

[6] Camblor M A, Corma A, Martínez A, Pérez-Pariente J. J Chem Soc, Chem Commun, 1992: 589

[7] Jappar N, Xia Q H, Tatsumi T. J Catal, 1998, 180: 132

[8] Gunther W R, Wang Y R, Ji Y W, Michaelis V K, Hunt S T, Griffin R G, Román-Leshkov Y. Nat Commun, 2012, 3: 1109

[9] Jinka K M, Lee S C, Park S E, Jasra R V. Stud Surf Sci Catal, 2008, 174B: 1187

[10] Nogier J P, Millot Y, Man P P, Shishido T, Che M, Dzwigaj S. J Phys Chem C, 2009, 113: 4885

[11] Li P, Liu G Q, Wu H H, Liu Y M, Jiang J G, Wu P. J Phys Chem C, 2011, 115: 3663

[12] Hammond C, Conrad S, Hermans I. Angew Chem Int Ed, 2012, 51: 11736

[13] Wolf P, Hammond C, Conrad S, Hermans I. Dalton Trans, 2014, 43: 4514

[14] Dijkmans J, Gabriëls D, Dusselier M, de Clippel F, Vanelderen P, Houthoofd K, Malfliet A, Pontikes Y, Sels B F. Green Chem, 2013, 15: 2777

[15] Tang B, Dai W L, Sun X M, Guan N J, Li L D, Hunger M. Green Chem, 


\section{Graphical Abstract}

Chin. J. Catal., 2015, 36: 801-805 doi: 10.1016/S1872-2067(14)60277-1

Incorporation of cerium atoms into Al-free Beta zeolite framework for catalytic application

Bo Tang, Weili Dai*, Xiaoming Sun, Guangjun Wu, Landong Li, Naijia Guan, Michael Hunger Nankai University, China; University of Stuttgart, Germany

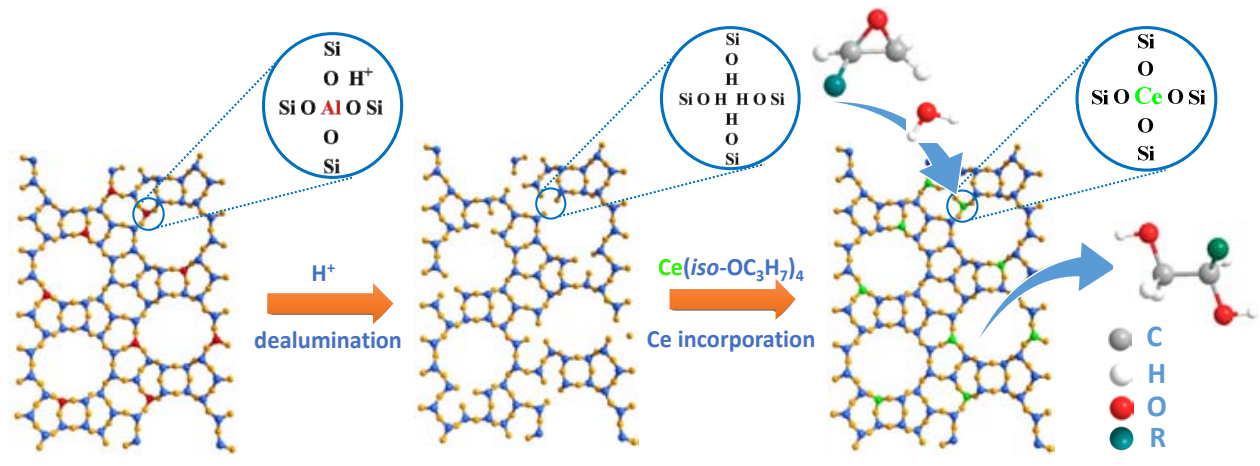

Preparation of Al-free Ce-Beta zeolite was realized for the first time by a facile and scalable two-step post-synthesis procedure and the material was used as a catalyst in a ring-opening hydration reaction.

2014, 16: 2281

[16] Tang B, Dai W L, Wu G J, Guan N J, Li L D, Hunger M. ACS Catal, 2014, 4: 2801

[17] Janas J, Gurgul J, Socha R P, Shishido T, Che M, Dzwigaj S. Appl Catal B, 2009, 91: 113

[18] Dzwigaj S, Millot Y, Krafft J M, Popovych N, Kyriienko P. J Phys
Chem C, 2013, 117: 12552

[19] Juttu G G, Lobo R F. Catal Lett, 1999, 62: 99

[20] Laha S C, Mukherjee P, Sainkar S R, Kumar R. J Catal, 2002, 207: 213

[21] Hunger M, Ernst S, Steuernagel S, Weitkamp J. Microporous Mater, 1996, 6: 349

\section{Ce-Beta分子筛的制备及其催化性能}

唐 波 ${ }^{\mathrm{a}}$, 戴卫理 ${ }^{\mathrm{a}}{ }^{*}$, 孙晓明 ${ }^{\mathrm{a}, \mathrm{b}}$, 武光军 ${ }^{\mathrm{a}}$, 李兰冬 ${ }^{\mathrm{a}}$, 关乃佳 ${ }^{\mathrm{a}}$, Michael Hunger $^{\mathrm{b}}$

a南开大学化学学院, 先进能源材料化学教育部重点实验室, 天津化学化工协同创新中心, 天津 300071

$\mathrm{b}^{\mathrm{b}}$ 斯图加特大学, 化学工程研究所, 德国斯图加特70550

摘要: 采用简单、易重现的两步后合成法成功制备了Ce-Beta分子篮. 制备过程中, H-Beta分子篮首先经过脱铝处理得到Si-Beta 分子篮, 然后再以异丙醇铈为前驱体, 通过干法浸渍的途径向 Si-Beta分子篮引入Ce (IV). 利用XRD, FT-IR, UV-Vis和 ${ }^{1}$ H MAS NMR等对其结构进行了表征, 结果表明, Ce(IV)物种以四配位的形式成功引入Beta分子篮的骨架, Ce原子进入分子篮骨架的机理 通过DRIFT光谱得以证实. 通过环氧化合物水合制备1,2-二醇反应对所制的Ce-Beta催化剂进行了催化性能评价.

关键词: Ce-Beta分子篎; 后合成; 脱铝; 开环水合; 环氧

收稿日期: 2014-11-04. 接受日期: 2014-12-04. 出版日期: 2015-06-20.

*通讯联系人. 电话/传真: (022)23500341; 电子信箱: weilidai@nankai.edu.cn

基金来源：国家自然科学基金(21373119); 教育部创新团队(IRT13022, IRT13R30); 111计划(B12015); 德国科学基金会.

本文的英文电子版由Elsevier出版社在ScienceDirect上出版(http://www.sciencedirect.com/science/journal/18722067). 